\title{
THE BROOKHAVEN ACCELERATOR TEST FACILITY INJECTION SYSTEM
}

\author{
X.J. Wang \\ Department of Physics, UCLA, Los Angeles, CA 90024 \\ H.G. Kirk, C. Pellegrini \\ Browkharen National Laboratory, Upton, NY 11973 \\ BNL -41891 \\ DE89 017599 \\ K.T. McDonald, D.P. Russell \\ Joseph Henry Laboratories, Princeton University, Princeton, NJ 08544
}

\begin{abstract}
The Brookhaven Acceierator Test Facility ( $\Lambda T F)$ consists of a $50-\mathrm{MeV} / \mathrm{c}$ electron linac and a high-brightness RF-gun both operating at $2856 \mathrm{MHs}$. An extremely short (a few picoseconds) electron pulse with a low transverse emittance is generated by the RF-gun. In order to preserve both longitudinal and transverse emittances, great care must be taken in ransporting the electron beam from the RF-gun to the linac. Wie describe the injection line, present first- and second-order lattice studies of the injection line, and study nonlinear effects on the emittence.
\end{abstract}

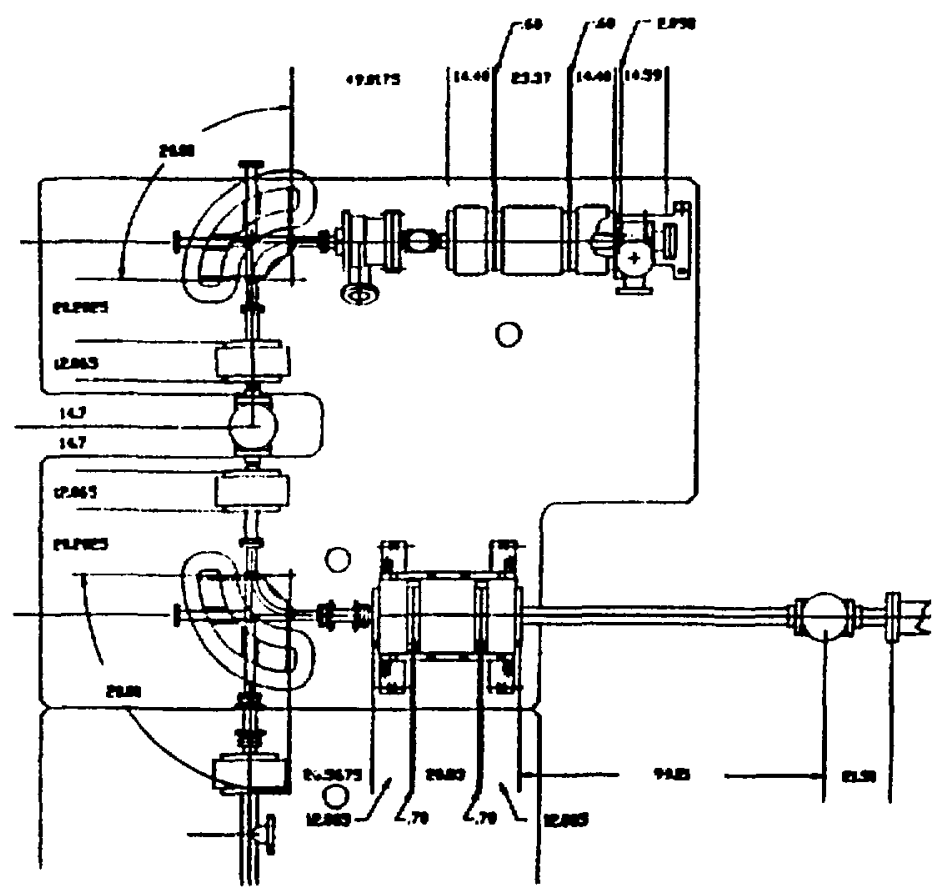

Figure 1: Detailed view of the gun-to-linac transport line.

\section{Introduction}

One of the most important developments in accelerator technology in the last few years is the photoinjector technology for high-brightness electron beams. ${ }^{1}$ The Brookhayen Accelerator Test Facility is dereloping this technology to produce high-quality beams for FEL, ${ }^{2}$ laser acceleration ${ }^{3,4}$ and other experiments. This paper presents the design of the ATF injection system, and calculates the transverse emittance and bunch-length behaviour.

The basic objective of the ATF injection system (Fig. 1) is to transfer an intense, low-emittance electron beam from the electron gun to the linac without a significant increase in beam emittance or bunch length; to provide the possibility of measuring the tranaverse and longitudinal emittance ${ }^{-6}$ and to perform momenturn selection and magnetic pulse compression. The ATF injection system consiats of two quadrupole triplets and a $180^{\circ}$ achromatic double bend. The firat triplet produces a waist at the median point between the dipoles, where a momentum-selection slit is located. The second triplet can be used to match the beam to the linac or to do emittance measurement. Several configurations of the injection aystem have been studied. First- and second-order beam propertiea of the injection line were calculated using the computer program TRANSPORT. The momentum resolution provided by the momentum-selection slit could reach $\pm 0.1 \%$. Higher-order effects on the beam emittance were first entimated with a one-dimensional model and then calculated uing numerical integration methods.

Table 1; Initial beam parameters.

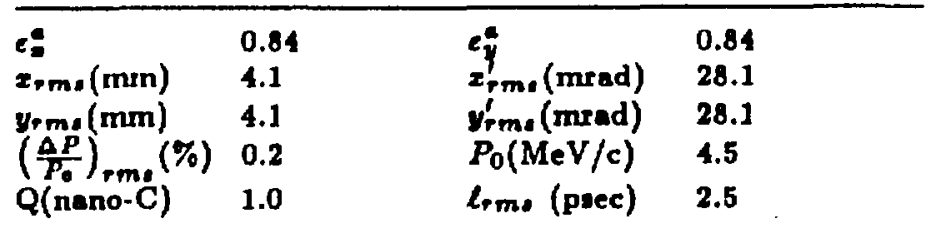

- 1- $\sigma$ geometric emittance in mm-mrad.

First- and second-order fattices

Beam parameters at the exit of the RF-gun are given in Table 1. We have studied several configurations of the injection line, depending on the quadrupole polarities and whether or not the first triplet is symmetric. Table 2 show beam parameters for three typical corsigurations. The FDF configuration hes amall horisontal amplitude overall while the vertical dimensions are very sensitive to field error and edge eftects caused by strong vertical focusing. Secondorder calculations show that correction sextupoles rould be helpful for vertical control; but it is rery difficult to find positions where the rertical betatron amplitude is large while the dispersion is nonsero so that second-order corrections be carried out.

Many problems associated with the FDF configuration can be olved by reversing the polarities of the quadrupoles of the two triplets. This leads to our second configuration (DFD of Table 2). This design has larger betatron amplitudes in the vertical direction at the entrance of the first dipole and a larger horisontal beam size at the beam waist. This problem can be handled by making the firat and the third quadrupoles of the first triplet nonsymmetric. As listed under configuration DFD' of Table 2, the beam sise can be reduced / 


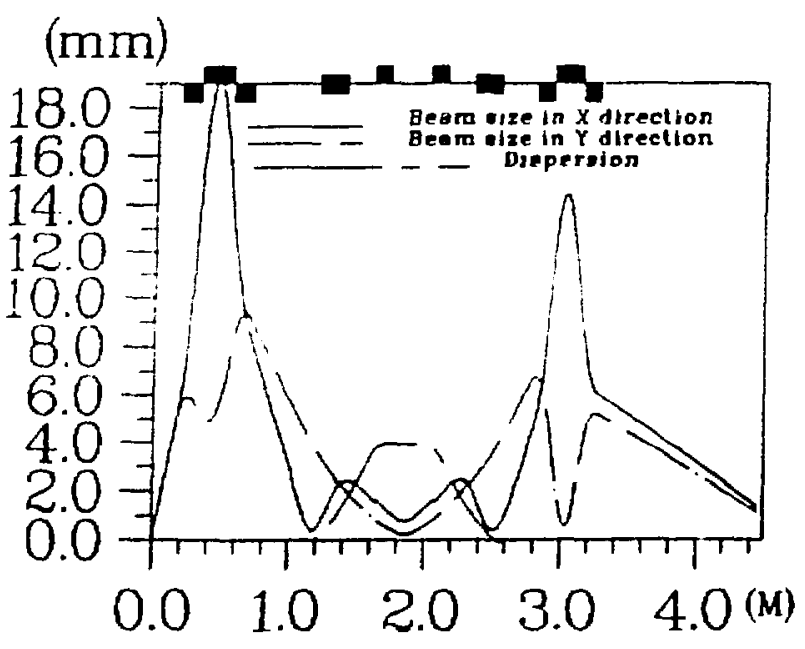

Figure 2t First-order calculation of the bearn envelopes (in $\mathrm{mm}$ ) and dispersion (in mm per \% of $\triangle P / P$ ) for the $A T F$ beamline configuration $D F D^{\prime}$ with $\Delta P / P=0.2 \%$, prior the adjustment of the $y$ waist.

at the entrances of dipoles and at the waist. Fig. 2 shows the frat-order beam sises and dispersion for the $\mathrm{DFD}$ injection line as calculated by TRANSPORT.

Second-order calculations show that there is little change (compared to first-order) in the horisontal beam enrelope, but a big distortion is observed in the rertical beam envelope. We have found that second-order efiects in $y$ can be reduced through the adjustment of the quadrupole parameters. Instead of locating the vertical beam waist in the halfway between the two dipoles as in the furst-order design, we put it downstream at the entrance of the focusing quadrupole. Fig.3 showe the second-order beam envelopes after the adjustment of the quadrupole strengths to the $D F D^{\prime}$ configuration.

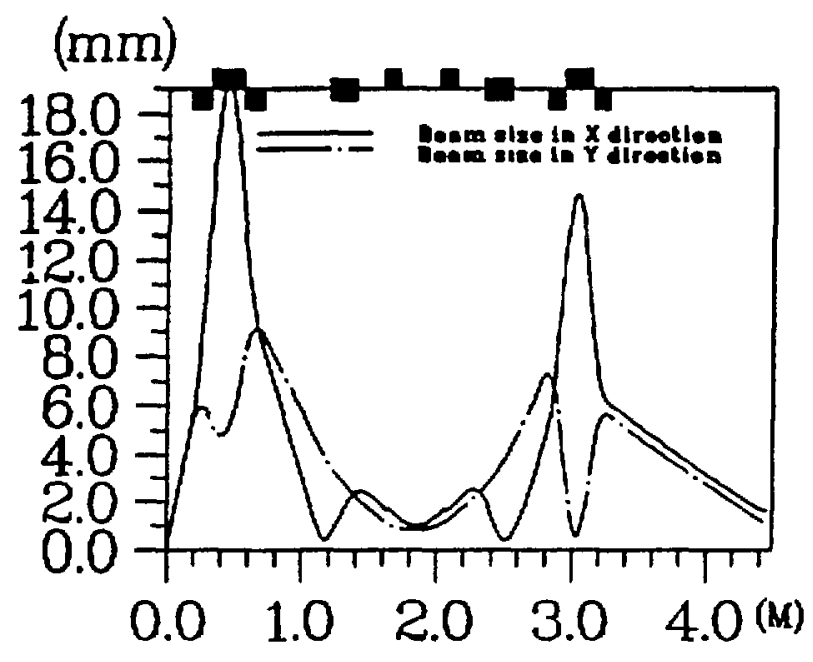

Figure 3: Second-order calculation of the beam envelopea (in $\mathrm{mm}$ ) for the ATF beamline configuration $\mathrm{DFD}^{\prime}$ with $\Delta P / P=0.2 \%$, after the adjustment of the $y$ waist.
Table 2i Beam parameters for three configurations.

\begin{tabular}{|c|c|c|c|}
\hline & FDF & DFD & $\mathrm{DFD}^{\prime}$ \\
\hline$X_{\text {mes }}$ & 13.823 & 16.168 & 19.212 \\
\hline$Y_{\text {mas }}$ & 17.246 & 17.092 & 9.033 \\
\hline 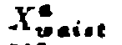 & 0.078 & 0.153 & 0.120 \\
\hline$Y_{\text {ueiat }}$ & 1.263 & 0.152 & 0.326 \\
\hline$x_{\text {tatat }}^{b}$ & 0.276 & 0.835 & 0.273 \\
\hline$Y_{\text {uatot }}$ & 1.544 & 1.070 & 0.807 \\
\hline$d_{m \in \bullet}$ & 3.925 & 3.913 & 3.913 \\
\hline$Y^{e}$ & 3.311 & 7.028 & 3.750 \\
\hline
\end{tabular}

- Firat-order calculation without energy opread (mm).

- Second-order calculation without energy apread ( $\mathrm{mm}$ ).

e Vertical beam sise at the entrance of the first dipole (mm).

\section{Emittance growth in a transport line}

Many studies of the emittance behaviour in a photoinjector RF-gun ${ }^{7,8}$ have been done, but few reports exint for the emittance growth in the tranuport line of short, highbrightness electron bunches.

Emittance growth in the magnetic transport line is mainly due to:

- Miomatch caused by linear opace charge.

- Nonlinear apace charge.

- Chromatic effecto.

- Nonlinear magnetic fields.

There are many theoretical ${ }^{0}$ and experimental ${ }^{10}$ studies of the opace-charge effect: on the transverse beam emittance in a transport line. We will now concentrate on chromatic and nonlinear magnetic fields effects.

In our emittance study, tranaverse gsometric emittance is expressed as

$$
c=\left(\left\langle x^{2}\right\rangle\left\langle x^{\prime 2}\right\rangle-\left(x x^{\prime}\right\rangle^{2}\right)^{\prime}
$$

A simple one-dimensional model is used to estimate emittance growth dus to higher-order effects. We will first congider the chromatic effects.

For simplicity, we now consider a sero-emittance beam with $x_{0}^{\prime}=0$ and nonsero $x_{0}$ pasaing through a thin lens, After the lens, we here $x=x_{0}$ and $x^{\prime}=x_{0}^{\prime}+\Delta x^{\prime}$. Including the chromatic effect, we obtain

$$
\Delta x^{\prime}=-\frac{x_{0}}{f(1+\delta)}
$$

where $f$ is the focal length of the lens, and $\delta=\Delta P / P_{0}$.

If we asaume no correlation between the transverse ponitions of the particles and their energies, then the emittance increase is

$$
\Delta e \approx\left(\left\langle x_{0}^{2}\right\rangle^{2}\left(1-2 \delta+\delta^{2}\right\rangle-\left(x_{0}^{2}\right)^{2}\langle 1-\delta\rangle\right)^{\frac{1}{2}} / f .
$$

Thus

$$
\Delta e=\left(x_{0}^{2}\right) \delta_{\mathrm{rma}} / f
$$

We can use the same model to derive a similar formula for higher-order geometric effects. Let us assume that the quadrupoles have midplane eymmetry and their fields up to fifth order are given by

$$
B=G_{1} x+G_{3} x^{3}+G_{5} x^{5},
$$




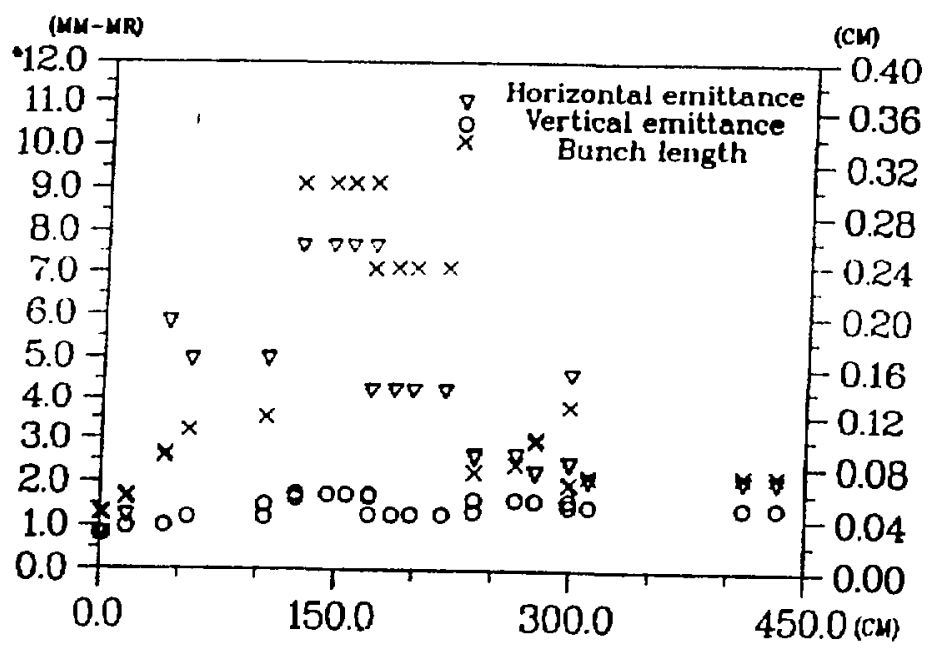

Figure 4: Emittance and bunch length vs. position.

where $G_{2 n+1}$ is the magnetic-field coefficient of the corresponding magnetic field.

At the focal plane of the quadrupole, we can calculate the emittance introduced by nonlinear terms using the following relations

$$
x=x_{0}+f x_{\text {out }}^{\prime}=-f S_{3} x_{0}^{3}-f S_{5} x_{0}^{5},
$$

and

$$
x^{\prime} \approx-\frac{x_{0}}{f},
$$

where $S_{8}=G_{8} /\left(f G_{1}\right), S_{8}=G_{\mathbf{B}} /\left(f G_{1}\right)$, and $f$ is the linear focal length of the quadrupole.

Subatituting $z$ and $z^{\prime}$ into equation (1), we have

$$
\begin{aligned}
\Delta \varepsilon^{2}= & S_{3}^{2}\left(\left\langle x_{0}^{0}\right\rangle\left\langle x_{0}^{7}\right\rangle-\left\langle x_{0}^{4}\right\rangle^{2}\right)+ \\
& S_{5}^{2}\left(\left\langle x_{0}^{10}\right\rangle\left\langle x_{0}^{b}\right\rangle-\left\langle x_{0}^{0}\right\rangle^{2}\right\rangle+ \\
& 2 S_{3} S_{5}\left(\left\langle x_{0}^{8}\right\rangle\left\langle x_{0}^{2}\right\rangle-\left\langle x_{0}^{0}\right\rangle\left(x_{0}^{4}\right)\right) .
\end{aligned}
$$

To calculate the moments of $x_{n}$, we suppose that the beam has the initial distribution $f\left(x_{0}\right)=A \exp \left(-x_{0}^{2} /\left(2 \sigma^{2}\right)\right)$, where $\sigma$ is the r.m.s. beam sire.

Case 1. $S_{5}=0$.

$$
\Delta e=4\left(\frac{\sigma}{d}\right)^{4} \frac{d^{2}}{f} \frac{\Delta B_{3}}{B_{0}} \frac{1}{I_{0}}\left(I_{6} I_{2}-I_{4}^{2}\right)^{\frac{1}{2}},
$$

where $d$ is a radius at which the nonlinear field (3) is known: $B_{0}=G_{1} d, \Delta B_{3}=G_{3} d^{3} ; I_{2 n}=\int_{0}^{R / \sqrt{2} \sigma} x^{2 n} \exp \left(-x^{2}\right) d x$, and $R$ is the radius of quadrupole.

Case 2. $S_{\mathbf{3}}=0$.

$$
\Delta \varepsilon=B\left(\frac{\sigma}{d}\right)^{0} \frac{d^{2}}{f} \frac{\Delta B_{B}}{B_{0}} \frac{1}{I_{0}}\left(I_{10} I_{2}-I_{b}^{3}\right)^{\frac{1}{2}},
$$

where $\Delta B_{5}=G_{5} d^{5}$.

Table 31 Nonlinear fielda for the first triplet.

\begin{tabular}{cccc}
\hline$Q_{1}$ & $Q_{2}$ & $Q_{3}$ \\
\hline$\Delta B_{3} / B_{0}(\%)^{*} 0.04$ & 0.32 & 0.04 \\
$\Delta B_{8} / B_{0}(\%)^{*}$ & 0.54 & 0.15 & 0.54 \\
\hline
\end{tabular}

- At $88.6 \%$ of aperture; $R=5.16 \mathrm{~cm}$.
We are now able to calculate the emittance growth due to higher-order effects. For the second quadrupole of the first triplet, $f_{0}=15.82 \mathrm{~cm}, \sigma_{-}=15.85 \mathrm{~mm}$ (the average r.m.s. horisontal beam sise inside the quadrupole), and $\delta=2 \times 10^{-3}$. Then the emittance increase caused by chromatic effect will be approximately $3.18 \mathrm{~mm}-\mathrm{mrad}$. The nonlinear fields of the second quadrupole are given in Table $3 .^{11}$ For $d=4.57$ $\mathrm{cm}$, the emittance growth caused by third- and fifth-order nonlinear field are approximately $1.5 \mathrm{~mm}$-mrad and $0.9 \mathrm{~mm}$ mrad, respectively.

For very short bunches, second-order effects related to the divergence of the beam could be very important. Bunch lengthening caused by second-order geometric abberation in drift space can be calculated by:

$$
\Delta \ell=\frac{L}{2}\left(x^{\prime 2}+y^{\prime 2}\right)
$$

for $x^{\prime}=y^{\prime}=30 \mathrm{mrad}$ and $L=1 \mathrm{~m}, \Delta \ell=0.9 \mathrm{~mm}$.

\section{Numerical study}

We have developed a tracking program for emittance atudy. The Runge-Kutte method was adopted in our program to solve the initial-value problem for a syatem of ordinary differential equationo. Chromatic effects are fully treated. We have also included nonlinear fields up to fifth order.

The emittence after each element in the firat triplet is given in Table 1. We find that the results ogree with our aimple model to within $30 \%$ error. A $\pm 1.6 \mathrm{~mm}$ square slit is placed at bearn waist to reduce the growth of both the transverse emittance and bunch length. A second slit at the exit of the second triplet, along with contoured edge of the dipoles, will restrict the emittance gromth to within a factor of 2. Emittances after each element of the injection line are plotted in Fig. 4. About $75 \%$ of the beam particles survive the cuts, with $15 \%$ being lost at the first slit, and another $10 \%$ being lost at the second slit.

\section{Conclusion}

It has been shown that it is possible to preserve transverse emittance in a low-energy beam-transfer line by use of alits and contoured edges of the dipole magnets. Bunch lengthening is induced by the large beam divergence out of the RF-gun, thus requiring strong focusing.

This rork is supported by the U.S. Department of Energy.

\section{References}

1. J.S. Fraser et al., p. 1705, Proceedings of the 1987 Particle Accelerator Conference (Washington, D.C.).

2. C. Pellegrini, Nucl. Instr. and Meth., A.272, 364 (1988).

3. R.B. Palmer, Particle Accelerators, 11, 81 (1980).

4. E.D. Courant, C. Pellegrini and W. Zakowics, Phyı. Rev. A 32, 2813 (1985).

5. K.T. McDonald and D.P. Russell, "Methode of Emittance Meanurement," Proceedings of the Joint US-CERN School on Observation, Diagnosis and Corrections in Particle Beamer(Capri, Italy, 1988).

6. K. Batchelor, H. Kirk, J. Sheehan, M. Woodle and K. McDonald, "Derelopment of a High Brightness Electron Gun for the Accelerator Test Facility at Brookhaven 
National Laboratory," Proceedings of the Earopean Particle Accelerstor Conference (1988); K.T. McDonald, IEEE Trans. Elec. Der. 35, 2052 (1988).

7. B.E. Carlsten and R.L. Sheffield, "Photoelectric injector design considerations," Proceedings of the 1988 Linac Conf. (Williansburg, VA).
8. Kwang-Je Kim, "RF and Space-Charge Effects in Laserdriven RF electron guns", LBL Report LBL - 25807 (Aug. 25, 1988) .

9. M. Reiner, IEEE Trans. Nucl. Sci. 32, 2201 (1985).

10. M. Reiser et al., Phy. Rev. Lett. 61, 2933 (1988).

11. T.R. Sherwood, "Harmonic Content of BNI Quadrupoles," BNL Internal Report MPS-LIN-Note 74-8.

Table 4: 'Transverse emittance after each element."

\begin{tabular}{|c|c|c|c|c|c|c|}
\hline$z(\mathrm{~cm})$ & $e^{b}$ & $\epsilon_{y}^{b}$ & $\varepsilon^{e}$ & $e_{y}^{e}$ & $e_{0}^{d}$ & $c_{y}^{d}$ \\
\hline 0.0 & 0.798 & 0.812 & 0.795 & 0.815 & 0.795 & 0.816 \\
\hline 2.058 & 0.798 & 0.812 & 0.795 & 0.815 & 0.795 & 0.815 \\
\hline 16.458 & 0.803 & 0.813 & 1.203 & 0.977 & 1.211 & 0.979 \\
\hline 40.428 & 3.749 & 1016 & 4.096 & 0.814 & 5.805 & 1.021 \\
\hline 55.428 & 3.616 & 0.944 & 3.046 & 1.111 & 4.928 & 1.207 \\
\hline 104.446 & $3.616=$ & 0.944 & 3.046 & 1.111 & 4.928 & 1.207 \\
\hline
\end{tabular}

- $1-\sigma$ emittance in mm-mrad.

e $\Delta P / P_{0}=0.2 \%$, all nonlinear terms are sero.
$\Delta P / P_{0}=0$, all nonlinear terms included.

$\Delta P / P_{0}=0.2 \%$, all noninear term are included.

\section{DISCLAIMER}

This report was prepared as an account of work sponsored by an agenuy of the United States Government. Neither the United States Gnvernment nor any agency thereof, nor any of their employees, makes any warranty, express or implied, or assumes any legal liability or responsibility for the accuracy, completeness, or usefulness of any information, apparatus, product, or process disclosed, or represents that its use would not infringe privately owned rights. Reference herein to any specific commercial product, process, or service by trade name, trademark, manufacturer, or otherwise does not necessarily constitute or inply its endorsement, recommendation, or favoring by the United States Government or any agency thereof. The vitws and opinions of authors expressed herein do not necessarily state or reflect those of the United States Government or any agency thereof. 